\section{EDITOR'S SUMMARY}

The growing recognition of and demand for formal data management plans (DMPs) is spurring academic and research libraries to consider how they can serve researchers to meet this need. Research data management services may include training in data management, consultation for plan writing and support with metadata elements and data repository choice. Libraries must develop expertise in research data management in the absence of clear or consistent guidance or practice, but useful direction is available through researchers' DMPs. The authors, representing several universities, collaborated on the development of a rubric to analyze and evaluate DMPs required by the National Science Foundation. Analysis of these DMPs, drawn from varied institutions, illustrates existing practices and has led to an assessment tool that can help libraries determine the services they should be able to offer researchers.

\section{KEYWORDS}

data set management research data sets research libraries academic libraries information services strategic planning

\section{Data Management Plans as a Research Tool}

by Lizzy Rolando, Jake Carlson, Patricia Hswe, Susan Wells Parham, Brian Westra and Amanda L. Whitmire

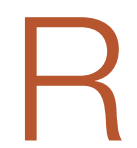
esearch datasets have gained wider acceptance as important, stand-alone scholarly products, and funding agencies such as the National Science Foundation (NSF) have introduced requirements for the creation of data management plans (DMPs). In response, academic and research libraries are devoting significant consideration, effort and resources toward expanding their roles to include research data management (RDM) services. RDM services can include training in data management best practices, consultations for writing DMPs and support for various data management components such as creating metadata or choosing appropriate data repositories.

To provide RDM support services, libraries will need to develop and maximize expertise in data curation and management within the library. Many university libraries are reorganizing to initiate service structures that can meet the demands of RDM services, but most will be doing so with limited resources and personnel. Further, DMP guidance from funding agencies varies widely, as do the Libraries are faced with the daunting task of creating, implementing, marketing and assessing new RDM services that will meet the demands of their community. How does a library decide where to start? How can a library determine where their investment will have the most impact?

The DMPs that researchers submit with grant proposals are a rich source of data that libraries can use to inform the development of their RDM services. As a document produced by researchers themselves, DMPs provide a window into the knowledge, capabilities and needs of both faculty members and their graduate students. A structured review of DMPs could identify gaps and weaknesses in faculty understanding and application of data management concepts and practices and identify the barriers in applying best practices. As such, the assessment of DMPs can uncover important insights about local RDM practices and aptitudes, which can then inform the development of RDM services. diverse practices of the research communities themselves.

Lizzy Rolando is research data librarian at Georgia Tech Library. She can be reached at lizzy.rolando<at>library.gatech.edu

Jake Carlson is research data services manager at University of Michigan Library. He can be reached at jakecar<at>umich.edu

Patricia Hswe is digital content strategist and head, ScholarSphere user services at Pennsylvania State University Libraries. She can be reached at pmh22<at>psu.edu

Susan Wells Parham is research data project librarian at Georgia Tech Library. She can be reached at susan.parham<at>library.gatech.edu Brian Westra is Lorry I. Lokey Science Data Services Librarian at University of Oregon Libraries. He can be reached at bwestra <at>oregon.edu Amanda L. Whitmire is assistant professor and data management specialist at Oregon State University Libraries. She can be reached at Amanda. whitmire<at>oregonstate.edu 
Past research efforts using DMPs have already uncovered interesting and important findings. A review of DMPs from the University of Illinois revealed that there was no statistically significant difference between DMPs from funded and unfunded NSF proposals, with respect to the proposed storage venue [1]. A study at Georgia Tech found that faculty regularly share large sections of DMP text, even across departmental boundaries [2].

In light of such potential value, collaborators from Oregon State University, University of Michigan, Pennsylvania State University, Georgia Institute of Technology and the University of Oregon have collaborated to develop an analytic rubric to assess NSF DMPs. An outcome of this IMLS-funded project is a rubric designed to be a research tool for academic librarians, to enable them to analyze large bodies of DMPs from their institutions for the purposes of better understanding the practices of the local communities. This tool enables librarians who may have no direct experience in applied research or RDM to become better informed about researchers' data practices and how library services can support them. Awareness of local practices is fundamental to providing RDM services that are tailored to the needs of an institution's faculty and students. For example, if a review of DMPs reveals that researchers routinely obligate certain library services in their DMPs, the library has a better idea of how to allocate limited resources for the highest impact.

Although tools such as the DMPTool (https://dmptool.org/) or DMP Online (https://dmponline.dcc.ac.uk/) help with the creation of a DMP, there is no standardized tool to aid with the evaluation of the quality of a DMP. Further, nothing has been developed to enable consistent, large-scale evaluation of DMPs for research purposes. As the collaborators on this project, we expect our rubric will fill the need for evaluation. Academic librarians need a wide array of tools to develop research data services and reach their full potential in this area. The analytic rubric developed and demonstrated during this project and the results of our research will add to the collective knowledge base of the academic librarianship community and bolster our ability to provide targeted, appropriate services in support of datadriven research.

In addition to the rubric, the project will produce a multi-institutional comparative analysis of DMPs that demonstrates the rubric. This analysis will ensure that the rubric is robust enough to produce valuable results at any library and provide a broad perspective on the data practices and needs of research scientists. While some practices and subsequent needs will be localized and unique to one institution, many will be the same across institutions. Our first small-scale review revealed that researchers rely on a wide variety of venues for sharing data. In our sample, websites were the most common method for publishing data, followed by journals or supplements to journals [3].

Our rubric will give librarians a means to utilize DMPs as a research tool that can inform decisions about which research data services they should provide. Whether a library is developing RDM services from scratch or looking to improve current RDM services, using the rubric to analyze DMPs will equip the library with the information they need to best support their community.

To learn more about the project and stay up-to-date with our progress, please visit

http://dmpresearch.library.oregonstate.edu/.

\section{Acknowledgements}

This project was made possible in part by the Institute of Museum and Library Services, grant number LG-07-130328. … Resources on next page 


\section{Resources Mentioned in the Article}

[1] Mischo, W. H., Schlembach, M. C., \& O’Donnell, M. N. (2014). An analysis of data management plans in University of Illinois National Science Foundation Grant Proposals. Journal of eScience Librarianship, 3(1): Article 3. D0l:10.7191/jeslib.2014.1060h

[2] Parham, S.W. \& Doty, C. (2012). NSF DMP content analysis: What are researchers saying? Bulletin of the American Society for Information Science \& Technology, 39 (1), 37-38. D0l:10.1002/bult.2012.1720390113

[3] Westra, B. (2015). Applying a rubric to data management plans to investigate data sharing [poster]. Poster session presented at the meeting of Force2015, Oxford, UK. 